\title{
A PERCEPÇÃO AMBIENTAL DO CONSUMIDOR CONSIDERANDO A ACV E UM PRODUTO DA INDÚSTRIA DE ERVA-MATE
}

\author{
Ronaldo José Seramim \\ Mestrando Profissional em Administração \\ Universidade Estadual do Oeste do Paraná - UNIOESTE \\ ronaldoseramim@yahoo.com.br
}

\section{Loreni Teresinha Brandalise}

Doutora em Engenharia de Produção

Docente Associada da graduação em Administração e do Mestrado Profissional em Administração Universidade Estadual do Oeste do Paraná - Cascavel

lorenibrandalise@gmail.com

\section{RESUMO}

Este estudo buscou identificar o grau de percepção do consumidor em relação às questões ambientais ao longo da Análise do Ciclo de Vida do produto (ACV) à base de Chá Mate. Para isso, o modelo Vapercom de Brandalise (2008) foi adaptado e aplicado ao público consumidor de chá mate gelado "Xima", produzido por uma indústria localizada no município de Laranjeiras do Sul, Paraná. Esse modelo possibilita à organização desenvolver ações sobre a gestão do produto na ótica da redução, reutilização e possibilidade de reciclagem. A metodologia é quanti e qualitativa, aplicada a uma amostra de 138 potenciais consumidores do produto em um processo que envolveu a caracterização do produto e do público pesquisado, identificação da percepção ambiental, do consumo ecológico e das etapas ACV. Ao final foi possível descrever a importância para organizações em aplicar o modelo e obter maior conhecimento sobre sua clientela, propiciando ações norteadas pela conduta do consumidor em relação ao produto. Os principais resultados indicam que a organização deve desenvolver ações mercadológicas para informar as fortes características ecológicas presentes no produto, pouco percebidas pelos consumidores.

Palavras-chave: ACV; Consumidor ecológico; Meio ambiente; Percepção ambiental.

\section{CONSUMER'S ENVIRONMENTAL AWARENESS CONSIDERING THE LCA AND A PRODUCT OF THE YERBA MATE INDUSTRY}

\section{ABSTRACT}

This study sought to identify the level of consumer perception on environmental issues regarding the product's Life Cycle Analysis (LCA) focused on yerba mate industry. For this, the Brandalise's (2008) VAPERCOM model was adapted and applied to consumers of iced tea Xima, produced by an industry in the municipality of Laranjeiras do Sul, Paraná. The model enables the organization to develop management actions seeking out reduction, reuse and recyclability of the product. The methodology is quantitative and qualitative, applied to a sample of 138 potential consumers of the product, in a process that involved the characterization of the product and the identification of consumers' environmental awareness, ecological consumption and LCA. We also described the importance of organizations to apply the model for greater insight for their customers, providing guided actions in consumer behavior regarding the product. The main results indicate that the organization should develop marketing actions to inform relevant ecological characteristics of the product, little noticed by consumers.

Key words: Environment; Environmental awareness; Green consumer; LCA. 


\section{INTRODUÇÃO}

A sociedade contemporânea compreende que os recursos naturais são finitos e alguns até escassos, por isso a necessidade do uso racional, domando, controlando e adequando o progresso ao bem-estar do ser humano, por meio da preservação do meio ambiente (Brandalise, 2012).

Por meio da discussão em torno dos recursos, produtos, consumo e impactos é que organizações passam a analisar as percepções do consumidor em relação ao meio ambiente e como podem impactar em seus processos internos e externos, neste caso, podem adotar um modelo de apoio à decisão empresarial, considerando o desenvolvimento sustentável. Em relação ao meio ambiente, as organizações podem avaliar a percepção do consumidor para alinhar estratégias integradas e impactantes em todo o ciclo de vida de um produto.

Lemke e Luzio (2014) afirmam que poucos estudos têm analisado como os consumidores verdes percebem a produção, o design do produto e as dimensões da análise do ciclo de vida (LCA - Life Cycle Assessment). Analisam, ainda, que existem lacunas importantes entre o que os consumidores verdes exigem e as condições ou a vontade de atender das empresas.

$\mathrm{O}$ modelo Vapercom (sigla que significa: VA=variável ambiental, PER=percepção e $\mathrm{COM}=$ comportamento de compra) foi desenvolvido por Brandalise (2008) para identificar as características ambientais dos produtos e comparar com as esperadas pelos consumidores de acordo com sua percepção, para auxiliar a tomada de decisão empresarial quanto à fabricação ou em relação ao marketing.

Em 2009, o Vapercom foi adaptado para analisar a percepção e o comportamento ambiental de universitários em relação ao grau de educação ambiental (Brandalise, Bertolini, Rojo, Lezana, \& Possamai, 2009), comprovando utilidade para análise sobre o comportamento do consumidor considerando sua percepção da variável ambiental, pois compreender o comportamento e os hábitos do consumidor diante de produtos com impacto ambiental reduzido pode orientar decisões de marketing com objetivo de obter vantagem competitiva (Reyes-Ricon, 2010; Castanho, Spers, \& Farah, 2006).

Neste estudo, o modelo foi utilizado para analisar a percepção do consumidor na Análise do Ciclo de Vida do produto (ACV) chá mate gelado "Xima", mapeando as características do produto, produzido por uma indústria de erva-mate. Busca-se, por meio desse estudo, compreender: qual é o nível de percepção do consumidor em relação às questões ambientais e em relação ao produto da empresa. Levando-se em consideração a $\mathrm{ACV}$, o objetivo do trabalho é identificar o grau de percepção do consumidor em relação às questões ambientais ao longo da ACV.

A ACV compreende alguns aspectos, desde a aquisição da matéria-prima até a disposição final, que possibilitam ações de suporte empresarial sobre a gestão do produto, na ótica da redução, reutilização e possibilidade de reciclagem (Brandalise, 2008). Portanto, serve de apoio à gestão organizacional industrial, ainda não aplicado em um produto à base de mate.

Outras abordagens ocorreram com produtos diversos, tais como Poliestireno Expandido (EPS) (Forlin, Brandalise, \& Bertolini, 2014); papel, papelão, editoria e gráfica; mecânica; metalúrgica; madeira e mobiliário; têxtil, vestuário, artefatos de tecidos e indústria de produtos alimentícios, e empresários industriais (Thomas, Sontag, \& Brandalise, 2014), produtos orgânicos (Debastiani, Tugoz \& Brandalise, 2016), dentre outros. Nestes estudos, a percepção "ecológica ou ambiental" foi analisada sob a ótica da prática ambiental e permitiu sugestões de melhorias às organizações pesquisadas. O modelo também foi apropriado quando aplicado ao público consumidor de jogos de videogame, considerando a substituição da mídia física por digital (Back \& Brandalise, 2015).

Este estudo se justifica porque é importante investigar se realmente a variável ambiental é considerada quando da tomada de decisão na compra ou consumo do Xima, e se há relação entre gênero e a preocupação com o meio ambiente, pois o modelo é constituído de etapas que vão desde a caracterização do produto até a definição de estratégias organizacionais. Assim, os resultados podem contribuir para o incremento de ações em relação ao produto ou à divulgação do mesmo, visando incremento de vendas.

A estrutura do trabalho se organiza em seções que apresentam, no referencial teórico, conceitos relacionados ao tema que serviram de base para esta pesquisa. Na seção 3 são apresentados os aspectos metodológicos relacionados à obtenção e tratamento dos dados. Na seção 4, apresentam-se as discussões, finalizando, na seção 5, com as considerações finais sobre os principais resultados obtidos com a pesquisa. 


\section{FUNDAMENTAÇÃO TEÓRICA}

O referencial teórico utilizado aponta contextualizações e esclarecimentos sobre as empresas e o meio ambiente, percepção ambiental, o comportamento e consumo ecológico, a análise do ciclo de vida do produto e o modelo Vapercom.

\subsection{As empresas e o meio ambiente}

Nos primórdios da industrialização, os problemas ambientais eram pouco expressivos, com indústrias mais espalhadas e escalas de produção reduzidas. As indústrias eram vistas como símbolos de crescimento, modernização e riqueza, e as exigências ambientais eram mínimas (Pilger, 2013). Com o tempo, a crescente ocorrência de sinistros ambientais, exploração desenfreada do meio ambiente para produção e desigualdades sociais evidentes pautam discussões em vários países, as organizações começam a perceber como o meio ambiente é importante para as gerações futuras e para a continuidade existencial das próprias empresas.

A partir da década de 1970, as conferências mundiais de meio ambiente e discussões importantes passaram a fazer parte da agenda de grandes países, incluindo avanços na legislação para controle de agressões aos recursos naturais não-renováveis (Brandalise, 2008). Um dos casos mais conhecidos na relação "meio ambiente e empresa" é o da organização americana 3M, que, em 1975, implantou uma política ambiental conhecida como 3P - Pollution Prevention Pays, para prevenir a poluição gerada nos processos de produção. Essa estratégia gerou economia para a empresa e redução de poluentes num período de 30 anos (Stadler \& Maioli, 2012).

No Brasil, a partir de 1988 com a promulgação da atual Constituição Federal, houve um grande avanço no quesito ambiental, apresentado no Capítulo VI (Stadler \& Maioli, 2012). Além dos tratados internacionais realizados posteriormente, há um grande ordenamento jurídico ambiental desde a Constituição Federal do Brasil de 1988, e desenvolve-se com várias outras leis estaduais, municipais, decretos, portarias, instruções e outras que regulam as questões ambientais e interferem diretamente nas organizações. Da mesma forma, os consumidores passam a ser mais perceptivos com relação a variável ambiental (Brandalise, 2008).

Pilger (2013) ressalta que normas e leis influenciam as empresas e que, dependendo do ramo de atuação, organizações não podem ser constituídas sem o devido licenciamento ambiental. Além disso, consumidores e fornecedores também influenciam fortemente na adoção de ações ambientais em toda cadeia produtiva, com impactos no ciclo de vida dos produtos, exigindo uma relação sustentável. Eckert, Neto e Boff (2015) estudaram pequenas e médias empresas do Vale do Caí no Rio Grande do Sul, e confirmaram fatores de influência que indicam a preocupação organizacional principalmente sobre a geração e destinação dos resíduos poluentes e a redução do consumo de energia. Além disso, utilizam canais de comunicação informais para repassar informações sobre iniciativas e práticas ambientais.

Essa dinâmica entre stakeholders demonstra a relevância do tema, por isso investiga-se a percepção ambiental dos consumidores, as influências no seu comportamento e efetivamente as razões que levam ao consumo. Para manter a imagem de empresa responsável, algumas passam a adotar "selos verdes" ou rótulos ecológicos (Atkinson \& Rosenthal, 2014) como uma forma de evidenciação das ações voltadas ao meio ambiente.

O primeiro e mais antigo selo verde em atuação no mercado foi criado na Alemanha em 1977, chamado de certificação Blue Angel, desenvolvido pelo governo alemão. Outros países também desenvolveram seus próprios selos. No Brasil, a Associação Brasileira de Normas Técnicas (ABNT) criou o selo de Qualidade Ambiental para certificar produtos, considerando o seu ciclo de vida (Stadler \& Maioli, 2012), a certificação e os rótulos ecológicos, que acabou atraindo consumidores ecológicos (Atkinson \& Rosenthal, 2014).

Dutra, Mazza e Menezes (2014) destacam que o número crescente de consumidores brasileiros interessados em produtos ecologicamente corretos irá, provavelmente, resultar em um aumento da demanda por informações claras sobre economia de recursos, redução da poluição e desperdício no processo de produção e utilização de componentes mais sustentáveis. Os rótulos ecológicos representam uma alternativa útil para indústrias para melhorar a sua comunicação com os consumidores.

Os estudos de Leite (2003), ao analisar a logística reversa, revelam que o novo consumidor cada vez mais se sensibiliza com aspectos ambientais do planeta e as possibilidades de impacto dos produtos no meio ambiente. Conjuntamente há um avanço na legislação de diversos países, visando responsabilizar as 
empresas pelo retorno de seus bens e materiais, evitando o impacto destes no meio ambiente, ao mesmo passo que as empresas passam a preocupar-se em manter a imagem corporativa, associada ao respeito, cuidado e preservação do meio ambiente.

\subsection{Percepção ambiental, comportamento e consumo ecológico}

Brandalise (2008, p. 117) considera a percepção como o reflexo aos estímulos que as pessoas recebem, ou seja, é o processo de "decodificação dos estímulos recebidos". Neste contexto, há uma série de fatores inter-relacionados, tais como consciência e confiança, que recebem influência social (cultura, subcultura, classe social, classe social, grupos de referência, família, ocupação e renda, necessidades pessoais, idade, motivação, percepção, atitude, aprendizagem, personalidade ou autoconceito, estilo de vida), influências de marketing (produto, preço, praça, promoção) e influências situacionais (ambiente físico, ambiente social, tempo, tarefa, condições momentâneas). Portanto, a percepção ambiental ocorre quando o consumidor decodifica os estímulos recebidos de produtos/marcas/empresas relacionados com a variável meio ambiente ou ambiental.

Bertolini (2004) e Brandalise (2008) utilizam alguns indicadores para observar a percepção ambiental baseados em ações individuais, tais como a reutilização e reciclagem do lixo; não queimar lixo; não deixar a torneira aberta ao escovar dentes, ao fazer a barba ou lavar calçadas; apagar as luzes e Tvs ao sair do ambiente; utilizar a capacidade máxima das máquinas de lavar; não jogar lixo na rua; e utilizar rascunhos ou aproveitar, ao máximo, o uso dos papéis.

Battistella, Grohmann, Mello e Radons (2013), quando destacam que outros atributos além do preço e qualidade são levados em consideração no momento da compra, apontam o marketing verde presente em rótulos como estímulo que aumenta a atratividade para determinado produto. Complementam sobre a existência de consumidores que percebem e observam o rótulo ambiental.

Estudos mostram que a consciência ambiental advém da percepção e que o comportamento advém da consciência ambiental (Brandalise, 2008). Frederico, Quevedo-Silva e Freire (2013) consideram o fator confiança entre a consciência ambiental e o consumo ambiental, pois precisa haver confiança para que o consumo de produtos ecologicamente corretos se consolide.

Acredita-se na mudança individual para atingir um nível macro de consciência e percepção ambiental. A ideia não é consumir menos nem mais, mas consumir melhor (Peixoto, \& Pereira, 2013). Grohmann, Battistella, Velter e Casasola (2012) destacam que a preocupação ambiental é alvo das gerações atuais e é frequentemente relacionada com o comportamento dos consumidores. As atitudes ambientais do cidadão têm um impacto substancial no comportamento ecológico e compromisso real para abordar a sustentabilidade ambiental de longo prazo (Dutta, 2014).

Monteiro, Giuliani, Zambon, Pizzinatto e Cunha (2012) descrevem que a consciência ecológica pode ser mensurada de acordo com os valores e as crenças dos consumidores. O consumidor consciente é aquele que pratica as premissas ecológicas, além disso busca informações da empresa, do processo de produção do produto ou serviço que não prejudicam o meio ambiente.

Frederico et al. (2013) realizaram uma pesquisa não-probabilística em nível nacional e identificaram que a relação entre consciência ambiental e a intenção de consumo ambiental é significativa. A confiança dos consumidores torna o gap entre consciência e consumo menor, que é explicada pela falta de confiança em relação à ética dos varejistas.

No entanto, nem sempre produtos com característica ambiental, ou orgânicos, são viáveis financeiramente. Certos casos indicam que os consumidores nem sempre estão dispostos a pagar um valor superior ao do mercado para adquirir um produto orgânico. É importante a observância do tipo de produto a ser produzido (Bertolini, Brandalise, Rojo, \& Lezana Correio, 2013).

Peixoto e Pereira (2013) analisam as convergências entre o discurso ambientalmente responsável e o comportamento de consumo, baseados na teoria de Argyris et al. (1985), e destacam que há um reconhecimento de que é certo adotar hábitos de consumo ambientalmente responsáveis, e também destacam que a comodidade, falta de interesse, impotência, condição financeira e falta de incentivo do governo são os principais limitadores da efetivação do comportamento ambientalmente responsável.

Dessa forma, mensurar o comportamento de compra ambientalmente responsável e consciente tem sido uma das principais dificuldades (Reyes-Ricon, 2010). Peixoto e Pereira (2013) concluem que seria impossível ter hábitos de consumo completamente favoráveis ao meio ambiente nas condições atuais em que vive a sociedade. Dessa forma, nem sempre o comportamento é coerente com o discurso ambientalmente responsável pela existência de elementos motivacionais e contextuais. Entretanto, alguns autores, tais como 
Castanho et al. (2006), afirmam que o consumidor dá preferência de compra às empresas que incentivem ou pratiquem a reciclagem.

Para Battistella et al. (2013), as crenças e o comportamento ambiental são comprovadamente antecedentes do consumo ecológico. Dessa forma, os consumidores tomam decisões baseados em estímulos que estão relacionados com a interpretação das informações mercadológicas transmitidas por uma organização e pela própria consciência do que é, ou não, ecologicamente correto (Monteiro et al., 2012). Neste ponto, ressalta-se o fator emocional, que "[...]é um preditor melhor do que o cognitivo para o consumo ecológico, pelo menos no que se refere ao conhecimento subjetivo" (Reyes-Ricon, 2010, p. 65).

Pesquisas na área de cosméticos (mulheres) indicam que o público conhece pouco sobre os produtos ecológicos, mas $95 \%$ apresenta elevado grau de afeto ecológico e elevado grau de preocupação ecológica, o que impacta na quantidade de pessoas que possui um comportamento de compra ecológica (Tamashiro, Silveira, Mantovani, \& Campanário, 2014).

O perfil do consumidor ecológico considera: saber a postura ambiental do fabricante antes de comprar; comprar produtos e embalagens de produtos fabricados com material reciclado; identificar os produtos ecologicamente corretos pela embalagem; adquirir produtos orgânicos, biodegradáveis, lâmpadas e eletrodomésticos que consomem menos energia; e pagar mais por um produto que não agride o meio ambiente (Bertolini, 2004).

Barboza e Filho (2013) analisaram a ideologia verde e o comportamento do consumidor tecnológico, e concluíram sobre a existência de alguns consumidores que não acreditam em tecnologia sustentável ou verde, argumentam sobre propagandas falsas, chamado greenwashing (maquiagem verde). O consumidor moderno focado no valor social da tecnologia possui predisposição ao verde, porém o ato da compra não reflete essa atitude por sempre existir um produto mais novo e moderno que o ecológico.

$\mathrm{O}$ fato de o consumidor estar atento às causas ambientais não indica que isso reflete em suas práticas de consumo (Monteiro et al., 2012). Estudos com universitários indicam consciência ambiental, no entanto, a prática do consumo valoriza o custo-benefício em detrimento da relação custo-conservação ambiental (Gomes, Gorni, \& Dreher, 2011), por isso algumas práticas de consumo não corroboram com a preservação. Portanto, a participação do público consumidor é relevante para detalhar o ciclo de vida dos produtos e adequá-los as exigências do mercado.

\subsection{Análise do Ciclo de Vida do Produto - ACV}

O ciclo de vida é o conjunto de todas as etapas necessárias, desde a extração dos recursos até sua destinação final, para que um produto cumpra sua função. A ACV é uma ferramenta técnica para a avaliação dos aspectos ambientais e dos impactos potenciais associados a um produto, compreendendo etapas que vão desde a retirada dos recursos da natureza até a disposição do produto final (Brandalise, 2008). A ACV consiste numa inevitável e valiosa opção para avaliar os produtos verdes e a eficácia do sistema (Lemke \& Luzio, 2014).

Para a análise de cada estágio do ciclo, a ACV depende muito da sensibilidade e consciência ambiental de quem realiza a análise, por isso é difícil fazer comparações entre produtos similares e ainda não é possível realizar uma análise completa do ciclo de alguns produtos (Brandalise, 2008).

As fases da ACV são: a definição do objetivo e escopo (compreende a condução do estudo, sua abrangência e suas limitações, a unidade funcional, a metodologia e os procedimentos necessários); a análise do inventário do ciclo de vida (a entrada e saída, coleta de dados sobre a aquisição da matéria-prima e energia, manufatura e transportes); a avaliação de impacto (processo qualitativo e quantitativo, com classificação, caracterização e valoração); e a fase de interpretação (que identifica os principais problemas, faz-se uma avaliação, análise de sensibilidade e tiram-se conclusões) (Chehebe, 1998).

\subsection{O modelo Vapercom}

Brandalise (2008, p.141) apresenta o modelo para "[...]identificar o grau de percepção da variável ambiental na cadeia produtiva, na ótica da redução, reutilização e reciclabilidade dos recursos, associada ao comportamento do consumidor". A partir da ACV, o modelo é aprimorado na intenção de agregar e quantificar informações para evidenciar a importância atribuída aos aspectos ambientais na tomada de decisão de compra e consumo.

Esse modelo possibilita à organização verificar se os consumidores valorizam os produtos considerados ecologicamente corretos, permitindo conhecer seu comportamento, fornecendo subsídios no 
planejamento de ações no sentido de manter ou lançar novos produtos no mercado, considerando suas expectativas (Brandalise, 2008).

São quatro etapas para a aplicação: 1 - a caracterização do produto e do potencial consumidor; 2 identificação do pesquisado, da percepção ambiental, do consumo ecológico e das etapas ACV; 3 identificação das discrepâncias (gaps) entre as características ambientais do produto e as que o consumidor percebe; e 4 - definição das oportunidades de ações de incremento ou ajustes. As aplicações e respectivas análises do modelo são descritas nas discussões.

A etapa de caracterização do produto utiliza da matriz apresentada na Figura 1.

\begin{tabular}{|c|c|c|}
\hline Fraco & Mediano & Forte \\
\hline $\begin{array}{l}\text { - Oriunda de recursos não renováveis } \\
\text { - Alto impacto ambiental na extração } \\
\text { - Alto impacto ambiental na } \\
\text { armazenagem e/ou transporte }\end{array}$ & $\begin{array}{l}\text { - Oriunda de recursos renováveis a longo } \\
\text { prazo } \\
\text { - Baixo impacto ambiental na extração } \\
\text { - Considerável impacto ambiental na } \\
\text { armazenagem e/ou transporte }\end{array}$ & $\begin{array}{l}\text { - Oriunda de recursos renováveis } \\
\text { - Impacto ambiental irrelevante na extração } \\
\text { - Baixo impacto ambiental na armazenagem } \\
\text { e/ou transporte }\end{array}$ \\
\hline $\begin{array}{l}\text { - Alto consumo de energia na criação e } \\
\text { processos de fabricação } \\
\text { - Alta utilização de insumos oriundos de } \\
\text { MP não renovável ou poluente } \\
\text { - Alta geração de resíduos, efluentes e } \\
\text { emissões } \\
\text { - Alto consumo de combustível no } \\
\text { transporte e distribuição }\end{array}$ & $\begin{array}{l}\text { - Considerável consumo de energia na } \\
\text { criação e processos de fabricação } \\
\text { - Considerável utilização de insumos } \\
\text { oriundos de MP não renovável ou poluente } \\
\text { - Considerável geração de resíduos, efluentes } \\
\text { e emissões } \\
\text { - Considerável consumo de combustível no } \\
\text { transporte e distribuição }\end{array}$ & $\begin{array}{l}\text { - Baixo consumo de energia na criação e } \\
\text { processos de fabricação } \\
\text { - Baixa utilização de insumos oriundos de } \\
\text { MP não renovável ou poluente } \\
\text { - Baixa geração de resíduos, efluentes e } \\
\text { emissões } \\
\text { - Baixo consumo de combustível no } \\
\text { transporte e distribuição }\end{array}$ \\
\hline $\begin{array}{l}\text { - Curto período de uso (vida útil) } \\
\text { - Alta necessidade de energia na } \\
\text { utilização do produto } \\
\text { - Alto potencial de contaminação } \\
\text { - Necessita de muita embalagem }\end{array}$ & $\begin{array}{l}\text { - Médio período de uso (vida útil) } \\
\text { - Baixa necessidade de energia na utilização } \\
\text { do produto } \\
\text { - Baixo potencial de contaminação } \\
\text { - Razoável necessidade de embalagem }\end{array}$ & $\begin{array}{l}\text { - Longo período de uso (vida útil) } \\
\text { - Não necessita de energia na utilização do } \\
\text { produto } \\
\text { - Não contaminante } \\
\text { - Necessita de pouca embalagem }\end{array}$ \\
\hline $\begin{array}{l}\text { - Sem possibilidade de reutilização } \\
\text { - Sem potencialidade de canibalização } \\
\text { (reaproveitamento de seus componentes) } \\
\text { - Sem possibilidade de reciclagem }\end{array}$ & $\begin{array}{l}\text { - Baixa potencialidade de reutilização } \\
\text { - Baixa potencialidade de canibalização } \\
\text { (reaproveitamento de seus componentes) } \\
\text { - Baixa potencialidade de reciclagem }\end{array}$ & $\begin{array}{l}\text { - Alta potencialidade de reutilização } \\
\text { - Alta potencialidade de canibalização } \\
\text { (reaproveitamento de seus componentes) } \\
\text { - Alta possibilidade de reciclagem }\end{array}$ \\
\hline $\begin{array}{l}\text { - Alta periculosidade e/ou toxidade } \\
\text { - Alto volume de material } \\
\text { - Não é biodegradável }\end{array}$ & $\begin{array}{l}\text { - Baixa periculosidade e/ou toxidade } \\
\text { - Baixo volume de material } \\
\text { - Baixa biodegradabilidade }\end{array}$ & $\begin{array}{l}\text { - Não perigoso e/ou tóxico } \\
\text { - Baixo volume de material } \\
\text { - É biodegradável }\end{array}$ \\
\hline
\end{tabular}

Figura 1. Matriz de característica de produto ecologicamente correto

Fonte: Brandalise (2008, p.152)

A identificação das características do produto é realizada diretamente pelo pesquisador, utilizando a Matriz, em que as linhas da Figura 1 representam as etapas ACV (matéria-prima, processo de produção, utilização do produto, pós-utilização e descarte). Considera-se característica ambiental forte o produto que tem origem de matéria-prima renovável, impacto ambiental irrelevante na extração, armazenagem e transporte; na produção e utilização consome pouca energia e têm baixa geração de resíduos sólidos, efluentes líquidos e emissões atmosféricas; além das demais características evidenciadas na figura (Brandalise, 2008).

\section{PROCEDIMENTOS METODOLÓGICOS}

Esta é uma pesquisa quantitativa pelo emprego de instrumentos estatísticos, tanto na coleta quanto no tratamento dos dados. É qualitativa quanto à caracterização do produto e proposição de ações empresariais, pois nela concebem-se análises aprofundadas em relação ao fenômeno estudado e visa observar as características não apontadas pelo estudo quantitativo. Quanto aos objetivos caracteriza-se como pesquisa descritiva, por utilizar técnica padronizada de coleta de dados e avaliar relações entre variáveis (Raupp \& Beuren, 2009).

A aplicação ocorreu em três etapas com duração de seis meses: (1) diagnóstico e caracterização do produto por meio de entrevista e visita na empresa, realizada no mês de abril de 2015; (2) Aplicação do 
questionário de coleta de dados com base no modelo de Brandalise (2008); (3) análise estatística e inferências sobre o perfil consumidor.

Um pré-teste com 10 respondentes foi aplicado para verificar se o instrumento de coleta apresenta fidedignidade, durante o mês de abril de 2015, com esclarecimentos ao grupo sobre a relevância da pesquisa. Observou-se que os respondentes não conseguem compreender as diferenças na análise ACV em relação ao produto Xima, e preocupam-se no descarte da garrafa pet.

O questionário foi aplicado a uma amostra de 138 potenciais consumidores do produto Xima, com abordagem presencial, no município de Laranjeiras do Sul, Paraná. A distribuição foi proporcional e intencional por conglomerados, no comércio local, escolas, universidades, instituições governamentais, com intuito de atingir o maior número de potenciais consumidores do produto (o Xima), e ocorreu durante a primeira quinzena do mês de maio de 2015 com recolhimento no dia seguinte ao da distribuição.

O cálculo da amostra foi baseado na fórmula de Costa Neto (1977), considerando um erro amostral de 5\%, com 95\% de confiança, e sabendo que a proporção populacional seguramente não é superior a 0,10 (o produto de referência não vem sendo comercializado pela empresa e sua proporção no mercado pesquisado é de $10 \%)$.

$$
n=\left(\frac{Z \alpha}{\varepsilon_{0}}\right) * p *(1-p)
$$

Aplicando a fórmula, $n=$ tamanho da amostra necessária; $Z \alpha=$ variável normal padronizada $Z$ para um nível de significância $\alpha$; $\varepsilon_{0}=$ erro amostral tolerável - expresso na mesma unidade variável coletada); $p$ $=$ proporção populacional, os dados são: $Z \alpha=1,96 ; \varepsilon_{0}=0,05 ; p=0,10$, resultando $n=138,29$, ou, 138 elementos ou amostras.

Para a obtenção de 138 respostas, foram distribuídos 166 documentos impressos, sendo que 21 retornaram em branco e 7 não retornaram. Portanto, trata-se de amostra composta apenas de pessoas com disponibilidade para voluntariamente despender tempo em responder.

Os dados foram tabulados e analisados em quatro etapas: 1 - a caracterização do produto e do potencial consumidor com uma análise qualitativa sobre as etapas da ACV e a classificação ambiental quanto à característica forte, mediana ou fraca de cada fase; 2 - identificação do pesquisado, da percepção ambiental, do consumo ecológico e das etapas ACV com tabulação dos dados e análises unidimensionais; 3 identificação das discrepâncias (gaps) entre as características ambientais do produto e as que o consumidor percebe com abordagem bidimensional; e 4 - definição das oportunidades de ações de incremento ou ajustes com sugestões para a organização de acordo com os resultados apresentados (Brandalise, 2008).

A etapa de caracterização do produto foi obtida por meio de três entrevistas e uma visita técnica, com a gerência geral (1), administradora (1) e gerente de vendas (1). Foram realizadas na indústria e a matriz de caracterização do produto (Figura 1) foi utilizada para identificar as características do item analisado em cada etapa da ACV.

Foi aplicado teste de independência com auxílio do software Action visando identificar a relação entre questões, a 5\% de significância, com as hipóteses: H0 - existe relação significativa entre o sexo e a influência pela propaganda, pelos amigos ou pela família em relação às questões ambientais; H1 - não há relação significativa entre o sexo e a influência pela propaganda, pelos amigos ou pela família em relação às questões ambientais (Martins, 2001). A etapa final de análises e proposições ocorreu em agosto de 2015, com entrega do relatório de respostas e sugestões à empresa.

\section{ANÁLISES E DISCUSSÕES DOS RESULTADOS}

A aplicação ocorreu na indústria de erva-mate localizada em Laranjeiras do Sul, Paraná, que atua no mercado de erva-mate (Ilex paraguariensis) e chá mate desde 1976, e possui certificação da Associação de Certificação do Instituto Biodinâmico Brasileiro (IBD). A empresa utiliza basicamente a matéria-prima da erva-mate orgânica, pois acredita na agricultura orgânica como uma forma sustentável de produção, promovendo e estimulando a biodiversidade e os ciclos biológicos. Assim como maioria das organizações industriais, houve mudanças com o tempo em relação à ação sobre o meio ambiente (Pilger, 2013), fazendo-a pensar estrategicamente a sustentabilidade ambiental.

Revista de Gestão Social e Ambiental - RGSA, São Paulo, v. 10, n. 2, p. 19-36, maio/ago. 2016. 


\subsection{Caracterização do produto}

O produto em estudo é o chá mate envasado em garrafa pet "Xima" que tem como base o chá mate, cuja matéria-prima básica é a erva-mate orgânica e água, produzida na região de Laranjeiras do Sul, Paraná. Atende as exigências legais ambientais e possui permissão para produção (Leite, 2003; Stadler \& Maioli, 2012; Pilger, 2013)

Com base na matriz de característica de produto ecologicamente correto do modelo Vapercom, foi elaborada a Tabela 1 com a característica ecológica analisada de acordo com a Matriz apresentada na Figura 1 .

Tabela 1. Caracterização do produto nas principais etapas ACV

\begin{tabular}{|c|c|c|c|}
\hline $\begin{array}{l}\text { Etapas da } \\
\text { ACV }\end{array}$ & \multicolumn{2}{|c|}{$\begin{array}{l}\text { Impactos ambientais relacionados à erva-mate orgânica utilizada na } \\
\text { fabricação do Xima da Indústria de Mate }\end{array}$} & $\begin{array}{l}\text { Característi- } \\
\text { ca ecológica }\end{array}$ \\
\hline \multirow{2}{*}{$\begin{array}{l}\text { Matéria- } \\
\text { prima }\end{array}$} & Origem dos recursos & $\begin{array}{l}\text { Médio. Recursos extraídos e renováveis em longo } \\
\text { prazo. Necessidade de planejamento de replantio. }\end{array}$ & Mediana \\
\hline & $\begin{array}{l}\text { Impacto ambiental na } \\
\text { extração }\end{array}$ & $\begin{array}{l}\text { Baixo. A erva-mate orgânica plantada tem poda } \\
\text { regular ano a ano, renovando-se a cada ano. }\end{array}$ & Forte. \\
\hline \multirow{3}{*}{$\begin{array}{l}\text { Processo } \\
\text { de } \\
\text { produção }\end{array}$} & Consumo de energia & $\begin{array}{l}\text { Baixo. Com planejamento de consumo de energia } \\
\text { e utilização de resíduos de madeira no processo } \\
\text { de secagem. }\end{array}$ & Forte \\
\hline & $\begin{array}{l}\text { Geração de resíduos } \\
\text { sólidos, efluentes líquidos } \\
\text { e emissões atmosféricas. }\end{array}$ & $\begin{array}{l}\text { Os resíduos da erva-mate no processo de secagem } \\
\text { não causam danos ao meio ambiente. A emissão } \\
\text { atmosférica é insignificante. }\end{array}$ & Forte \\
\hline & $\begin{array}{l}\text { Consumo de combustível } \\
\text { no transporte/distribuição }\end{array}$ & $\begin{array}{l}\text { O consumo de energia utilizado no transporte } \\
\text { interno do produto é baixo. }\end{array}$ & Forte \\
\hline \multirow{4}{*}{ Utilização } & Vida útil do produto & Alto & Forte \\
\hline & Necessidade de energia & Não há & Forte \\
\hline & $\begin{array}{l}\text { Potencial de contaminação } \\
\text { ao meio ambiente }\end{array}$ & Não há & Forte \\
\hline & Embalagem & $\begin{array}{l}\text { Baixo (a garrafa pet não ocasiona risco na } \\
\text { utilização do produto). }\end{array}$ & Forte \\
\hline \multirow{3}{*}{$\begin{array}{l}\text { Pós- } \\
\text { utilização }\end{array}$} & $\begin{array}{l}\text { Possibilidade de } \\
\text { reutilização }\end{array}$ & Não há. & Fraco \\
\hline & $\begin{array}{l}\text { Potencialidade de } \\
\text { reaproveitamento de } \\
\text { componentes }\end{array}$ & Não há. & Fraco \\
\hline & $\begin{array}{l}\text { Possibilidade de } \\
\text { reciclagem }\end{array}$ & Há possibilidade de reciclagem & Forte \\
\hline \multirow{3}{*}{ Descarte } & $\begin{array}{l}\text { Periculosidade ou } \\
\text { toxidade. }\end{array}$ & Não há & Forte \\
\hline & Volume do material & Baixo & Forte \\
\hline & Biodegradabilidade & $\begin{array}{l}\text { Não no que diz respeito à embalagem. O produto } \\
\text { em si é biodegradável. }\end{array}$ & Fraco \\
\hline
\end{tabular}

Fonte: Pesquisa aplicada (2015) 
Além da matéria-prima (erva-mate) para a fabricação do Xima, existem outros itens essenciais: a água tratada e o acompanhamento na indústria; gás carbônico para produção do refrigerante; garrafa pet para embalagem. A principal preocupação da empresa é voltada ao descarte da embalagem (garrafa pet), que não é tóxica, mas demora anos para sua decomposição na natureza já que não é biodegradável, entretanto é $100 \%$ reciclável.

Seria ideal analisar o produto, considerando todas as matérias-primas em todo ciclo de vida, que demandaria muito tempo, trabalho e dificuldades para mensurar algumas variáveis, mas pode-se analisar o produto a partir das principais matérias-primas e etapas da ACV (Brandalise et al., 2014). A empresa adota políticas ambientais voltadas à redução e uso racional de recursos naturais durante a fabricação do produto, além de campanhas para incentivo ao plantio de árvores de Erva-Mate, essas atitudes também representam economia para a organização (Stadler \& Maioli, 2012).

\subsection{Aplicação do instrumento de coleta de dados}

Em relação aos respondentes, dos 138 pesquisados, 78 (56,52\%) representam pessoas do sexo feminino e $60(43,48 \%)$ do sexo masculino (Tabela 2). A maior presença de mulheres na amostra permite apontar que estas tendem a ter atitudes mais favoráveis em relação a produtos verdes (Reyes-Ricon, 2010). Mulheres também têm comportamento favorável à reciclagem, considerando a separação do lixo domiciliar, enquanto homens parecem ser mais resistentes (Romeiro, Prearo, \& Cordeiro, 2011). Estas situações ficaram evidenciadas nesta amostra, pois, do total de mulheres pesquisadas, $57(73,08 \%)$, separa o lixo que pode ser reciclado e o dispõe para coleta.

Quanto à idade, a maioria está na faixa dos 21 a 30 anos (35,51\%), e com renda familiar de 1 a 4 salários mínimos $(51,45 \%)$ (Tabela 2).

Tabela 2. Dados demográficos e questões sobre ACV

\begin{tabular}{|c|c|c|}
\hline Questão & Respostas & Percentual \% \\
\hline \multirow{2}{*}{ Sexo } & Feminino & $56,52 \%$ \\
\hline & Masculino & $43,48 \%$ \\
\hline \multirow{5}{*}{ Idade } & Até 20 anos & $18,12 \%$ \\
\hline & Entre 21 e 30 anos & $35,51 \%$ \\
\hline & Entre 31 e 40 anos & $28,26 \%$ \\
\hline & Mais de 41 anos & $17,39 \%$ \\
\hline & Não respondeu & $0,72 \%$ \\
\hline \multirow{6}{*}{ Renda } & Até 1 salário mínimo & $11,59 \%$ \\
\hline & De 1 a 4 salários mínimos & $51,45 \%$ \\
\hline & De 4 a 7 salários mínimos & $25,36 \%$ \\
\hline & De 7 a 10 salários mínimos & $7,25 \%$ \\
\hline & Mais de 10 salários mínimos & $2,90 \%$ \\
\hline & Não respondeu & $1,45 \%$ \\
\hline \multirow{6}{*}{$\begin{array}{c}\text { Onde você obtém informações sobre as } \\
\text { questões ambientais no dia a dia? }\end{array}$} & Amigos & $0,72 \%$ \\
\hline & Escola & $9,42 \%$ \\
\hline & Família & $1,45 \%$ \\
\hline & Mídia & $81,88 \%$ \\
\hline & Rótulos/embalagens & $5,80 \%$ \\
\hline & Não respondeu & $0,72 \%$ \\
\hline \multirow{2}{*}{$\begin{array}{l}\text { Você sabe o que é ACV (análise do } \\
\text { ciclo de vida do produto desde a }\end{array}$} & Não & $31,88 \%$ \\
\hline & Sim & $27,54 \%$ \\
\hline
\end{tabular}




\begin{tabular}{c|c|c}
\hline matéria-prima até o descarte) & Tenho dúvidas & $40,58 \%$ \\
\hline Você sabe que o produto que você usa & Não & $2,90 \%$ \\
\cline { 2 - 3 } causa impacto ao meio ambiente? & Sim & $81,88 \%$ \\
\cline { 2 - 3 } & Tenho dúvidas & $12,32 \%$ \\
\cline { 2 - 3 } & Não respondeu & $2,90 \%$ \\
\hline
\end{tabular}

Fonte: Pesquisa aplicada (2015)

Quando perguntados sobre a fonte de obtenção de informações sobre questões ambientais, $81,88 \%$ responderam que é a mídia (tv, rádio, jornal, revistas) (Tabela 2). Destacam-se aqui argumentos apresentados por Castanho et al. (2006) sobre a participação da mídia na influência do comportamento consumista das pessoas, na produção de resíduos no meio ambiente. Além da conclusão de Reyes-Ricon (2010, p. 66) que apesar de "[...]críticos e céticos com relação ao marketing verde custem a acreditar na sua eficácia em promover o desenvolvimento sustentável, a orientação ecológica nas decisões de consumo é o elemento principal que poderá levar a mudanças nos padrões produtivos".

Acerca da pergunta relacionada com a ACV, observou-se que $72,46 \%$ dos respondentes não sabiam e tinham dúvidas sobre o significado da Análise do Ciclo de Vida do produto, o que prejudica uma análise mais criteriosa das questões sobre a percepção das ações ambientais da empresa em relação as etapas ACV. E quando perguntados se sabiam que o produto que usam causa impacto no meio ambiente, as respostas foram $81,88 \%$ afirmando que sim, $12,32 \%$ possuem dúvidas, $2,9 \%$ não responderam e 2,9\% não sabiam.

\subsubsection{Conjunto percepção ambiental}

Em relação à percepção ambiental, foram efetivadas sete perguntas com opções de resposta: sempre, frequentemente, algumas vezes, pouquíssimas vezes e nunca (Escala de Likert). De acordo com Brandalise (2008), essas questões estão relacionadas com a conduta ambiental no cotidiano considerando os elementos de redução e conservação de recursos no consumo, reutilização e reciclabilidade. As respostas estão descritas na Tabela 3.

Tabela 3. Frequência de respostas do conjunto percepção ambiental

\begin{tabular}{|c|c|c|c|c|c|}
\hline CONJUNTO 02 - PERCEPÇÃO AMBIENTAL & 总 & 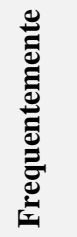 & 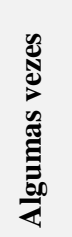 & 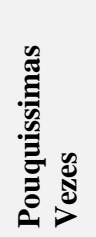 & $\stackrel{\text { שֶ }}{\Xi}$ \\
\hline Antes de jogar algo no lixo, você pensa em como poderia reutilizá-lo? & 16 & 25 & 73 & 14 & 10 \\
\hline Você é adepto da reciclagem? (3 pessoas sem resposta). & 36 & 41 & 37 & 16 & 5 \\
\hline $\begin{array}{l}\text { Você separa o lixo que pode ser reciclado (papel, plástico, alumínio, } \\
\text { vidro, metais) e os dispõe para coleta? (4 pessoas sem resposta) }\end{array}$ & 50 & 26 & 33 & 14 & 11 \\
\hline $\begin{array}{l}\text { Apaga as luzes, desliga TV, aparelho de som, ventilador / aquecedor } \\
\text { quando sai do ambiente? }\end{array}$ & 88 & 24 & 14 & 11 & 1 \\
\hline $\begin{array}{l}\text { Procura não deixar a torneira aberta ao escovar os dentes ou ao fazer a } \\
\text { barba? ( } 2 \text { pessoas sem resposta) }\end{array}$ & 93 & 22 & 12 & 5 & 4 \\
\hline Você utiliza os dois lados dos papéis, ou reutiliza rascunhos? & 60 & 41 & 27 & 5 & 5 \\
\hline Você evita imprimir coisas desnecessárias? & 79 & 35 & 13 & 5 & 6 \\
\hline TOTAIS (957 respostas / 9 sem resposta) & 422 & 214 & 209 & 70 & 42 \\
\hline
\end{tabular}

Fonte: Pesquisa aplicada (2015)

Dos totais apresentados, 9 campos ficaram sem resposta, de um total de 966 (Tabela 3). Observa-se, nestas questões, o predomínio da resposta "sempre", exceto na questão se o consumidor pensa como poderia reutilizar algo antes de jogar no lixo, onde maior parte optou por "algumas vezes". Além disso, na questão sobre a pessoa ser adepta da reciclagem também houve maior número de respostas entre: frequentemente, 
algumas vezes e sempre. Demonstra que pessoas acreditam que a reciclagem compensa (Castanho et al., 2006), no entanto, aspectos subjetivos sobre a percepção e a economia financeira merecem atenção, já que o público acaba conciliando economia de recursos com a financeira.

É importante ressaltar que o comportamento ambientalmente responsável não está relacionado apenas ao benefício ambiental, mas também pessoal, e, na maioria das vezes, financeiro com vantagem econômica, como a economia de água, energia, reutilização de produtos, compra de eletrodomésticos e lâmpadas de baixo consumo (Peixoto, \& Pereira, 2013).

Brandalise (2008) propõe a tabulação dos resultados de acordo com a Tabela 4. Os valores atribuídos às questões alternativas de respostas para a classificação foram: para $\mathrm{A}$ (sempre) $=4$ pontos; para $\mathrm{B}$ (frequentemente) $=3$ pontos; para $\mathrm{C}$ (algumas vezes) $=2$ pontos; para $\mathrm{D}$ (pouquíssimas vezes) $=1$ ponto; e para $\mathrm{E}$ (nunca) $=0$.

Tabela 4. Alocação de pesos e elaboração do grau de percepção ambiental

\begin{tabular}{|c|c|c|}
\hline (a) $\mathrm{N}^{\circ}$ RESPOSTAS & (b) VALORES & (a X b) RESULTADO \\
\hline$A=422$ & 4 & 1688 \\
\hline $\mathrm{B}=214$ & 3 & 642 \\
\hline $\mathrm{C}=209$ & 2 & 418 \\
\hline $\mathrm{D}=70$ & 1 & 70 \\
\hline $\mathrm{E}=42$ & 0 & 0 \\
\hline \multicolumn{2}{|c|}{ (c) SOMA DOS RESULTADOS } & 2818 \\
\hline \multicolumn{2}{|c|}{ (d) $\mathrm{N}^{\circ}$ DE QUESTÕES } & 957 \\
\hline \multicolumn{2}{|c|}{$(\mathrm{e}=\mathrm{c} / \mathrm{d})$ RESULTADO } & 2,94 \\
\hline
\end{tabular}

Fonte: Dados da pesquisa (2015)

Para viabilizar os cálculos de mensuração dos indicadores desse conjunto, utiliza-se a classificação do grau de percepção ambiental (Tabela 5).

Tabela 5. Classificação do grau de percepção ambiental

\begin{tabular}{cc}
\hline Grau de percepção em relação às questões ambientais & Valores \\
\hline A) Possui alta percepção ecológica & Entre 3,3 e 4,0 \\
\hline B) Possui percepção ecológica & Entre 2,5 e 3,2 \\
\hline C) Possui potenciais traços de percepção ambiental & Entre 1,7 e 2,4 \\
\hline D) Possui poucos traços de percepção ambiental & Entre 0,9 e 1,6 \\
\hline E) Não possui percepção ecológica. & Até 0,8 \\
\hline
\end{tabular}

Fonte: Brandalise (2008, p. 156)

As escalas de classificação obedecem a intervalos de 0,7 pontos com a divisão: entre 3,3 e 4,0; entre 2,5 e 3,2; entre 1,7 e 2,4; entre 0,9 e 1,6; e até 0,8 (Brandalise, 2008). Conforme esta classificação, o resultado 2,94 (Tabela 4) mostra que os pesquisados possuem percepção ecológica. Assim como em outros estudos, o modelo permitiu identificar a percepção ecológica (Back \& Brandalise, 2015; Brandalise et al., 2009; Forlin et al., 2014; Thomas et al., 2014).

\subsubsection{Conjunto consumo ecológico}

Para analisar as respostas obtidas no conjunto sobre consumo ecológico foi utilizado o mesmo método de alocação de pesos do conjunto percepção, apontando os resultados mostrados na Tabela 6. 
Tabela 6. Frequência de resposta - consumo ecológico

\begin{tabular}{|c|c|c|c|c|c|}
\hline CONJUNTO 03 - CONSUMO ECOLÓGICO & 离 & 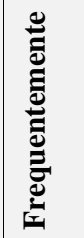 & 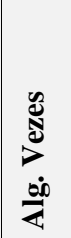 & 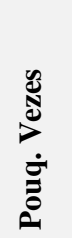 & 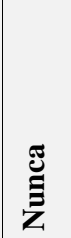 \\
\hline $\begin{array}{l}\text { Você considera a variável ambiental quando da compra de um produto? ( } 5 \\
\text { sem resposta) }\end{array}$ & 7 & 21 & 56 & 35 & 14 \\
\hline $\begin{array}{l}\text { Ao comprar você se deixar influenciar pela propaganda, pelos amigos ou } \\
\text { pela família em relação às questões ambientais? }(2 \mathrm{sem} \text { resposta) }\end{array}$ & 2 & 13 & 52 & 39 & 30 \\
\hline $\begin{array}{l}\text { Ao comprar, você procura saber se o fabricante pratica ações ambientais? ( } 3 \\
\text { sem resposta) }\end{array}$ & 1 & 14 & 29 & 47 & 44 \\
\hline $\begin{array}{l}\text { Ao comprar, você valoriza o fabricante que tem 'postura' ecologicamente } \\
\text { correta? ( } 2 \text { sem resposta) }\end{array}$ & 13 & 20 & 41 & 35 & 27 \\
\hline $\begin{array}{l}\text { Antes da compra você verifica rótulos e embalagens, para identificar um } \\
\text { 'produto' ecologicamente correto? (1 sem resposta) }\end{array}$ & 9 & 15 & 36 & 45 & 32 \\
\hline $\begin{array}{l}\text { Procura comprar produtos e/ou embalagens fabricados com material } \\
\text { reciclado ou que tem potencial para serem reciclados? (1 sem resposta) }\end{array}$ & 8 & 19 & 44 & 40 & 26 \\
\hline Você verifica o consumo de energia quando da compra de um produto? & 45 & 18 & 23 & 31 & 21 \\
\hline Você compra produtos biodegradáveis? (1 sem resposta) & 6 & 28 & 53 & 40 & 10 \\
\hline $\begin{array}{l}\text { Você se dispõe a pagar mais por um produto ecologicamente correto? ( } 2 \text { sem } \\
\text { resposta) }\end{array}$ & 10 & 19 & 52 & 34 & 21 \\
\hline $\begin{array}{l}\text { Você se dispõe a mudar de marca de produto para auxiliar na conservação } \\
\text { do meio ambiente? ( } 1 \text { sem resposta) }\end{array}$ & 23 & 29 & 54 & 27 & 4 \\
\hline $\begin{array}{l}\text { Você pagaria mais por um caderno fabricado com papel reciclado ou } \\
\text { proveniente de árvore reflorestada? }\end{array}$ & 24 & 30 & 41 & 35 & 8 \\
\hline TOTAIS (1500 respostas / 18 sem resposta $=1518)$ & 148 & 226 & 481 & 408 & 237 \\
\hline
\end{tabular}

Fonte: Dados da pesquisa (2015)

Neste conjunto de questões, a maioria das respostas concentrou-se entre "algumas vezes" e "pouquíssimas vezes". A análise da pontuação obtida nesse conjunto deve ser realizada de acordo com a alocação de pesos e elaboração do grau de consumo ecológico, seguindo a metodologia apresentada na variável percepção na Tabela 4. A soma dos resultados com peso fica em 2640, dividido pelo número de respostas de 1500, resulta em 1,76. A seguir, utiliza-se a classificação da Tabela 7.

Tabela 7. Classificação do comportamento de compra e consumo ecológico

Grau de consumo de produtos ecologicamente corretos Valores

\begin{tabular}{ll}
\hline A) Consumidor ecológico & Entre 3,3 e 4,0 \\
\hline B) Grande possibilidade de tornar-se um consumidor ecológico & Entre 2,5 e 3,2 \\
\hline C) Potencial possibilidade de tornar-se um consumidor ecológico & Entre 1,7 e 2,4 \\
\hline D) Fraca possibilidade de tornar-se um consumidor ecológico & Entre 0,9 e 1,6 \\
\hline E) Não é um consumidor ecológico & Até 0,8
\end{tabular}

\section{Fonte: Brandalise (2008)}

Com o resultado de 1,76, pode-se verificar que o consumidor pesquisado classificou-se como "potencial possibilidade de tornar-se um consumidor ecológico". A partir da opinião de Leite (2003), é possível concluir que há uma sensibilidade do potencial consumidor em relação aos impactos que o produto pode causar no meio ambiente.

Quando se utiliza o termo "potencial possibilidade" de tornar-se consumidor ecológico, considera-se que este público possui crenças e um comportamento ambiental propício a tornar-se um futuro consumidor ecológico (Battistella et al., 2013). Com base no resultado da pesquisa, neste caso, não há como validar a dimensão emocional (Reyes-Ricon, 2010). Denota também, que a empresa deverá repassar informações 
claras sobre economia de recursos, ações de redução da poluição e do desperdício, como indicam Dutra et al. (2014).

\subsubsection{Questões sobre o produto}

As questões sobre o produto foram incluídas com a intenção de obter mais informações sobre os consumidores potenciais, e algumas são adicionais ao modelo de Brandalise (2008). Foi possível identificar que $45,65 \%$ usa ou já utilizou o produto Xima, enquanto 54,35\% não. As razões para não utilizar foram obtidas por pergunta aberta, e são: não conhecer o produto (34,06\% do total); por não estar dentre as opções nas lojas $(14,49 \%)$; pela qualidade do produto $(2,17 \%)$; por não ter interesse $(1,45 \%)$; por não gostar $(0,72 \%)$; não ter hábito $(0,72 \%)$ e não ter oportunidade de experimentar $(0,72 \%)$.

Apesar de 54,35\% não utilizar o produto, 82,61\% compraria o Xima. Quando questionados se pagariam mais caro, $73,19 \%$ afirmaram que não; $24,64 \%$, sim e $2,17 \%$, não respondeu. $O$ fato de que consumidores não estão dispostos a pagar mais por um produto orgânico corrobora com os resultados de Bertolini et al. (2013). Nota-se que o consumidor não está disposto a pagar mais caro pelo produto, visto o seu baixo envolvimento com o mesmo (Atkinson, \& Rosenthal, 2014), já que maior parte também indicou não ter utilizado.

Em relação à preferência por chá mate gelado, com gás ou natural, os dados demonstraram que $73,19 \%$ optam pelo natural e 22,46\%, com gás; e 4,35\%, não respondeu. No entanto, não foi possível aprofundar se a preferência se dá por razões ambientais, de saúde ou econômicas. No entanto, assim como o estudo de Frederico et al. (2013), há uma relação significativa ou expressiva entre a consciência ambiental, neste caso evidenciada no resultado da percepção e na intenção de consumo.

\subsubsection{Conjunto de etapas ACV}

Os dados obtidos neste conjunto de questões "etapas da ACV” estão representados na Tabela 8.

Tabela 8. Dados da etapa ACV

\begin{tabular}{|c|c|c|c|c|c|c|}
\hline & CONJUNTO 04 - ETAPAS ACV & \multirow{2}{*}{ 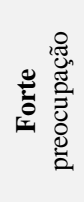 } & \multirow{2}{*}{ 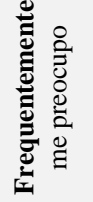 } & \multirow{2}{*}{ 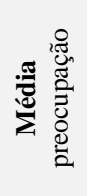 } & \multirow{2}{*}{ 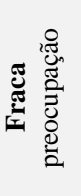 } & \multirow{2}{*}{ 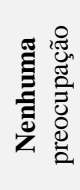 } \\
\hline $\begin{array}{l}\text { Em } \\
\text { com }\end{array}$ & $\begin{array}{l}\text { relação à matéria-prima (Erva-Mate) indique o grau de preocupação } \\
\text { : }\end{array}$ & & & & & \\
\hline 27 & Origem dos recursos (se são renováveis) (1 sem resposta) & 22 & 34 & 51 & 19 & 11 \\
\hline 28 & Impacto ambiental na extração (e no transporte) & 27 & 36 & 45 & 23 & 7 \\
\hline \multicolumn{7}{|c|}{$\begin{array}{l}\text { Em relação ao processo de produção, indique o grau de preocupação } \\
\text { com: }\end{array}$} \\
\hline 29 & Consumo de energia (na produção) & 25 & 26 & 44 & 27 & 16 \\
\hline 30 & $\begin{array}{l}\text { Geração de resíduos sólidos, efluentes líquidos e emissões } \\
\text { atmosféricas }\end{array}$ & 31 & 30 & 44 & 19 & 14 \\
\hline 31 & $\begin{array}{l}\text { Consumo de combustível na armazenagem e/ou transporte e } \\
\text { distribuição ( } 2 \text { sem resposta) }\end{array}$ & 22 & 26 & 45 & 31 & 12 \\
\hline \multicolumn{7}{|c|}{ Em relação à utilização do produto, indique o grau de preocupação com: } \\
\hline 32 & Vida útil do produto & 40 & 33 & 36 & 21 & 8 \\
\hline 33 & Necessidade de energia & 21 & 41 & 46 & 21 & 9 \\
\hline 34 & Potencial contaminação ao meio ambiente & 41 & 29 & 42 & 17 & 9 \\
\hline 35 & Embalagem (tipo e/ou volume) (5 sem resposta) & 25 & 36 & 41 & 23 & 8 \\
\hline \multicolumn{7}{|c|}{$\begin{array}{l}\text { Em relação à pós-utilização do produto, indique o grau de preocupação } \\
\text { com: }\end{array}$} \\
\hline 36 & Possibilidade de reutilização & 21 & 42 & 43 & 21 & 11 \\
\hline 37 & $\begin{array}{l}\text { Potencialidade de reaproveitamento de componentes ( } 2 \text { sem } \\
\text { resposta) }\end{array}$ & 19 & 39 & 44 & 24 & 10 \\
\hline 38 & Possibilidade de reciclagem (1 sem resposta) & 35 & 33 & 44 & 19 & 6 \\
\hline \multicolumn{2}{|r|}{ Em relação ao descarte do produto, indique o grau de preocupação com: } & & & & & \\
\hline
\end{tabular}

Revista de Gestão Social e Ambiental - RGSA, São Paulo, v. 10, n. 2, p. 19-36, maio/ago. 2016. 


\begin{tabular}{l|l|l|l|l|l|l}
\hline 39 & Periculosidade ou toxidade & 68 & 20 & 29 & 12 & 9 \\
\hline 40 & Volume de material (incluindo embalagem) (4 sem resposta) & 28 & 36 & 43 & 18 & 9 \\
\hline 41 & Biodegradabilidade & 31 & 25 & 49 & 20 & 13 \\
\hline \multicolumn{2}{c|}{ TOTAIS (2055 respostas / 15 sem resposta) } & $\mathbf{4 5 6}$ & $\mathbf{4 8 6}$ & $\mathbf{6 4 6}$ & $\mathbf{3 1 5}$ & $\mathbf{1 5 2}$ \\
\hline \multicolumn{2}{c|}{ Fonte: Dados da pesquisa (2015) }
\end{tabular}

Nesse conjunto de questões (Tabela 8), observa-se mediana preocupação em todas as etapas da $\mathrm{ACV}$, com destaque para a "utilização do produto" em que de houve forte e frequente preocupação com maior número de respostas. A preocupação com a "pós-utilização" e "descarte" foi evidente, especialmente quanto à periculosidade obteve quantidade expressiva de marcações.

Para a tabulação dos dados obtidos, utiliza-se novamente a Tabela 4: Alocação de pesos e elaboração do grau de percepção, de consumo ecológico e de preocupação em relação à ACV. Obtém-se um indicador de 2,38 que permite verificar a classificação do grau de preocupação do consumidor amostrado em relação à ACV na Tabela 9.

Tabela 9. Classificação do grau de preocupação /ACV

\begin{tabular}{cc}
\hline Grau de preocupação em relação às etapas da ACV & Valores \\
\hline A) Forte preocupação & Entre 3,3 e 4,0 \\
\hline B) Frequente preocupação & Entre 2,5 e 3,2 \\
\hline C) Mediana preocupação & Entre 1,7 e 2,4 \\
\hline D) Fraca preocupação & Entre 0,9 e 1,6 \\
\hline E) Nenhuma preocupação & Até 0,8 \\
\hline
\end{tabular}

Fonte: Brandalise (2008, p.158)

O resultado confirma que há "mediana preocupação" com as características ambientais ao longo do ciclo de vida do produto (Tabela 9). O potencial consumidor pode apresentar preocupações diferentes dependendo do tipo de produto que está sendo analisado (Back \& Brandalise, 2015; Brandalise et al., 2009; Forlin et al., 2014; Thomas et al., 2014). Este resultado pode indicar que o consumidor realmente não possui total atenção com as etapas ACV.

Os resultados em cada etapa da $\mathrm{ACV}$ permitem identificar onde há mediana e frequente preocupação do consumidor em relação às questões ambientais (Brandalise, 2008). Portanto, a Tabela 10 apresenta as discrepâncias entre o que o consumidor percebe e as características do produto.

Tabela 10. Caracterização do produto versus preocupação do consumidor

\begin{tabular}{lcc}
\hline \multicolumn{1}{c}{ CICLO DE VIDA DO } & CARACTERÍSTICAS DO & PREOCUPAÇÃO DO \\
PRODUTO & PRODUTO ECOLOGICAMENTE & CONSUMIDOR \\
\hline Matéria-prima & CORRETO & Mediana preocupação $(2,32)$ \\
\hline Processo de produção & Forte $(3,3)$ & Mediana preocupação $(2,19)$ \\
\hline Utilização do produto & Forte $(3,3)$ & Mediana preocupação $(2,44)$ \\
\hline Pós-utilização & Forte $(3,3)$ & Mediana preocupação $(2,36)$ \\
\hline Descarte & Mediana $(1,7)$ & Frequente preocupação $(2,54)$ \\
\hline
\end{tabular}

Fonte: Adaptado de Brandalise (2008)

Nas fases ciclo de vida, a matéria-prima, produção e utilização são caracterizadas como "forte" (Tabela 1), enquanto a pós-utilização e descarte como "mediana", por considerar o material plástico que não é biodegradável, porém $100 \%$ reciclável. O indicador numérico das características foi atribuído de acordo com os limites mínimos apresentados na Tabela 8.

Já a preocupação do consumidor é mediana, com exceção do descarte, onde a discrepância é maior e pode ser visualizada na Figura 2. 


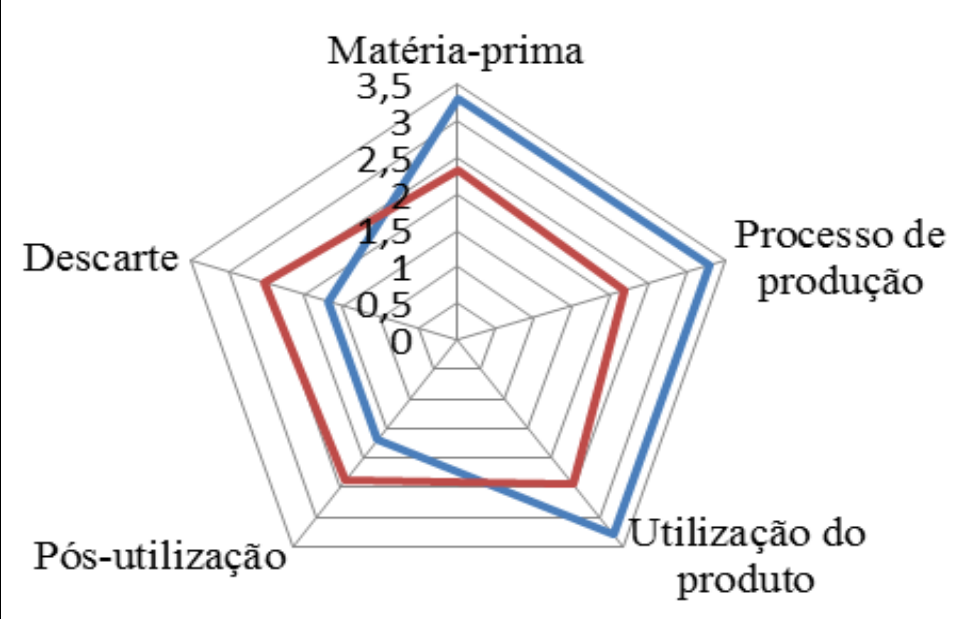

CARACTERÍSTICAS DO PRODUTO

—PREOCUPAÇÃO DO CONSUMIDOR

Figura 2. Gaps entre o produto e a preocupação do consumidor

Fonte: Adaptado de Brandalise (2008)

A Figura 2 permite realizar a última fase do modelo Vapercom, que pressupõe a definição das oportunidades de ações de incremento ou ajustes para reduzir o gap existente, que são:

1. Abordar um diálogo aberto com consumidores e esclarecer a utilização de certos materiais no produto. Reforçar sobre as potenciais consequências da remoção de alguns componentes. Para isso, são necessárias estratégias de marketing e produção para além de exploração do comportamento de compra, mas as outras fases do consumo (pós-utilização e descarte). Além disso, pode-se direcionar ações de marketing verde para o público do sexo feminino, considerando relação significativa.

Uma forma de promover a confiança e as atitudes positivas dos consumidores é utilizar rótulos ecológicos que fornecem explicações detalhadas sobre o produto e aumentam a credibilidade. No entanto, depende do alto ou baixo envolvimento do consumidor com o produto e do tipo de produto. Com o baixo envolvimento do produto, os consumidores tendem a confiar no rótulo e o alto envolvimento leva os consumidores a não observância do rótulo como fator determinante (Atkinson \& Rosenthal, 2014).

2. Adotar parcerias com organizações de catadores e instituições para promover campanhas de recolhimento e reutilização dos resíduos do produto. Para resolver pontos fracos destacados na Figura 2.

3. Futuramente a organização pode analisar a seleção de materiais (por exemplo, uso de outras opções para substituir a garrafa pet), em uma distribuição eficiente (por exemplo, usando menos / baixo impacto / embalagens reutilizáveis).

As sugestões 1 e 3 corroboram com as contribuições de Lemke e Luzio (2014). É importante ressaltar que os fabricantes devem abordar as emoções negativas evocadas por embalagens ecologicamente responsáveis e não assumir que a alternativa "verde" será avaliada favoravelmente, especialmente a nível emocional (Koenig-Lewis, Palmer, Dermody, \& Urbye, 2014).

No entanto, no momento de efetivar o consumo, aqueles consumidores ecológicos ocupados podem ser mais influenciados pelos preços ou outros atributos não ambientais do produto, ao invés de características verdes (Belk, 1975; Belk, DeVinney, \& Eckhardt, 2005; Atkinson \& Rosenthal, 2014).

Como há indicações de que o sexo impacta no consumo ecológico e influencia no marketing verde, foi realizada uma análise bidimensional da relação entre sexo e a questão "Ao comprar você se deixa influenciar pela propaganda, pelos amigos ou pela família em relação às questões ambientais?" Para analisar estatisticamente, foi aplicado o Teste de Independência, considerando 5\% de significância. As classes adjacentes foram unidas visando não deixar frequências com menos de 5 dados (Martins, 2001). 
Tabela 11. Sexo versus influência pela propaganda em relação às questões ambientais

\begin{tabular}{l|r|r|r|r}
\hline & \multicolumn{5}{|l}{$\begin{array}{l}\text { Ao comprar você se deixa influenciar pela propaganda, pelos amigos ou pela } \\
\text { família em relação às questões ambientais? }\end{array}$} \\
\hline Sexo & Sempre e Frequentemente & Algumas vezes & Pouquíssimas vezes & Nunca \\
\hline Feminino & 6 & 38 & 15 & 17 \\
\hline Masculino & 9 & 14 & 24 & 13 \\
\hline
\end{tabular}

Fonte: Dados da pesquisa (2015)

O teste de independência retornou p-valor de 0,00564 , portanto existe relação significativa entre a variável sexo com a influência por propaganda ou amigos sobre questões ambientais.

\section{CONSIDERAÇÕES FINAIS}

Dentre os resultados, ressalta-se a forte presença da mídia no repasse de informações quanto às questões ambientais, e nas dúvidas que os consumidores têm sobre a ACV, que impacta no conjunto de questões "preocupação com a ACV", onde prevaleceu mediana preocupação.

Cabe investigar os fatores relacionados e adotar estratégias de transmissão de informações sobre a ACV tanto na organização quanto por meio da mídia. Essa transmissão de informações deve considerar a conclusão de Lemke e Luzio (2014), de que o consumidor e a empresa devem possuir uma relação de confiança, evitar o ceticismo do consumidor e insatisfação com maquiagem verde e estabelecer a credibilidade e transparência de informações.

Não significa que a empresa não deve utilizar um marketing verde, pois o estudo de Koenig-Lewis et al. (2014) conclui que as emoções e a racionalidade dirigem o comportamento de compra pró-ambiental. Além disso, as emoções são mediadoras da intenção de compra, com um resultado diferente ao da racionalidade no processo (Koenig-Lewis et al., 2014; Reyes-Ricon, 2010).

Outros resultados em relação à renda indicam que a organização tem um quadro específico de público com faixa de renda no município pesquisado, assim, a empresa pode dedicar ações direcionadas, como, por exemplo, a estratégia de penetração no mercado para precificação do produto. A empresa também pode centralizar alguns esforços em relação à preferência, que, de acordo com os dados, apontam para um maior consumo do chá mate gelado sem gás (natural).

A maioria dos consumidores pesquisados possui compreensão sobre a importância do consumo ecológico, no que diz respeito ao impacto que os produtos podem causar no meio ambiente, pois possui percepção ecológica, corroborando com outras aplicações do modelo de Brandalise (2008). Já quanto à $\mathrm{ACV}$, o potencial consumidor carece de esclarecimentos.

Pode-se dizer que o produto tem mais características ecologicamente corretas (em cada etapa da $\mathrm{ACV})$ do que o consumidor percebe. O público classificou-se com potencial possibilidade de tornar-se um consumidor ecológico, possibilitando desenvolver ações de marketing informativas para estimular a compra do produto e até adotar a rotulagem ambiental dentro das normas ISO.

A amostra de 138 potenciais consumidores do produto permitiu realizar comparações e apontamentos sobre a influência das mulheres no comportamento ambientalmente correto (Romeiro et al., 2011); o fator emocional envolvido e os impactos nas organizações e nos produtos (Koenig-Lewis et al., 2014; Reyes-Ricon, 2010); a reciclagem dos produtos e a percepção do consumidor (Castanho et al., 2006); o discurso e o comportamento ambientalmente responsável (Peixoto, \& Pereira, 2013); a influência de selos ambientais em relação ao consumo (Atkinson, \& Rosenthal, 2014); além do design do produto e da disposição de consumidores verdes para pagar mais (Bertolini et al., 2013; Lemke, \& Luzio, 2014).

Ao final, destaca-se a importância em aplicar o modelo Vapercom nas organizações, pois indicou oportunidades de ações para estimular o consumo consciente do produto pesquisado. Foi possível contribuir com informações ao fabricante por avaliar o fator emocional, a confiança do consumidor ecológico, incluir questões específicas sobre o produto e aplicar testes estatísticos em amostras probabilísticas. Quanto ao modelo Vapercom, ocorreu evolução em relação aos estudos anteriores, ao adaptar o modelo à realidade do produto a ser analisado, permitindo amplas abordagens gerenciais e teóricas.

Quanto às limitações do estudo, é relevante ressaltar que a pesquisa foi aplicada a um público específico e trata da relação com um único produto, portanto, os resultados não podem ser generalizados. Pesquisas futuras podem ser realizadas com públicos diferenciados, considerando todas as matérias-primas

Revista de Gestão Social e Ambiental - RGSA, São Paulo, v. 10, n. 2, p. 19-36, maio/ago. 2016. 
em todo o ciclo de vida, e outras análises estatísticas bidimensionais podem ser efetivadas para ampliar a discussão entre a percepção de diferentes grupos de consumidores de diferentes produtos.

\section{REFERÊNCIAS}

Atkinson, L., \& Rosenthal, S. (2014) Signaling the green sell: the influence of Eco-Label source, argument specificity, and product involvement on consumer trust. Journal of Advertising, 43(1), 33-45.

Back, V. T., \& Brandalise, L. T. (2015) Videogames e a variável ambiental: análise da disposição dos consumidores em substituir a aquisição de seus jogos de mídia física, por jogos de mídia digital. Anais do Simpósio Internacional de Gestão de Projetos, Inovação e Sustentabilidade, São Paulo, SP, Brasil, 4.

Barboza, M. N. L., \& Filho, E. J. M. A. (2013) Ideologia verde e o comportamento do consumidor tecnológico: preferência de uso e justificação. Revista Pretexto, 14(4), 98-117.

Battistella, L. F., Grohmann, M. Z., Mello, C. I., \& Radons, D. L. (2013) Consumo ecológico entre as mulheres: análise de antecedentes. Revista Gestão Organizacional, 6(2), 42-55.

Belk, R. W. (1975) Situational variables and consumer behavior. Journal of Consumer Research, 2, 157-64.

Belk, R. W., Devinney, T., \& Eckhardt, G. (2005) Consumer ethics across cultures. Consumption, Markets \& Culture, 8 (3), 275-89.

Bertolini, G. R. F. (2004) Modelo de avaliação da percepção dos consumidores em relação aos produtos ecologicamente corretos. Dissertação de Mestrado, Universidade Federal de Santa Catarina, Florianópolis, SC, Brasil.

Bertolini, G. R. F., Brandalise, L. T., Rojo, C. A., \& Lezana Correio, A. G. R. (2013) A viabilidade financeira no desenvolvimento de produtos ecológicos valorizados pelos consumidores. Revista de Gestão e Projetos - GeP, 4(3), 01-29.

Brandalise, L. T. (2008) A percepção do consumidor na análise do ciclo de vida do produto: um modelo de apoio à gestão empresarial. Cascavel, PR: Edunioeste.

Brandalise, L. T. (2012) Desenvolvimento sustentável e o setor público. In L. T. Brandalise \& R. K. Nazzari (Orgs). Políticas de sustentabilidade: responsabilidade social corporativa das questões ecológicas, 19-68. Cascavel, PR: Edunioeste.

Brandalise, L. T., Bertolini, G. R. F., Rojo, C. A., \& Lezana, A. G. R. (2014) Classificação de produtos ecologicamente corretos. Revista Metropolitana de Sustentabilidade, 4(2), 3-24.

Brandalise, L. T., Bertolini, G. R. F., Rojo, C. A., Lezana, A. G. R, \& Possamai, O. (2009). A percepção e o comportamento ambiental dos universitários em relação ao grau de educação ambiental. Revista Gestão \& Produção, 16(2), 273-285.

Castanho, S. C. R., Spers, E. E., \& Farah, O. E. (2006) Custos e benefícios para o consumidor na ação da reciclagem. Revista de Administração Mackenzie - RAM, 7(4), 78-98.

Chehebe, J. R. B. (1998) Análise do ciclo de vida de produtos: ferramenta gerencial da ISO 14000. Rio de Janeiro: Qualitymark.

Costa Neto, P. L. de O. (1977) Estatística. São Paulo: Edgard Blucher.

Debastiani, S. M.,Tugoz, J. E., \& Brandalise, L. T. (2016) A percepção de educandos em relação às ações do PNAE voltadas ao desenvolvimento sustentável. Revista Ibero-Americana de Ciências Ambientais - RICA, $7(1)$.

Dutra, C. J. C., Mazza, A. A., \& Menezes, L. M. L. de. (2014) Innovation in sustainable products: crosscultural analysis of bi-national teams. Revista de Gestão Ambiental e Sustentabilidade - GeAS, 3(2), 149164.

Dutta, S. (2014) Components of ecological behaviour and consumer attitude towards sustainable green environment: an empirical analysis on kolkata citizens. Globsyn Management Journal, 8 (1/2), 53-63. 
Eckert, A., Neto, S. L. H. C., \& Boff, D. S. (2015) Iniciativas e práticas ambientais das pequenas e médias empresas do Vale do Caí - RS. Revista de Gestão Ambiental e Sustentabilidade - GeAS, 4(1), 108-123.

Frederico, E., Quevedo-Silva, F., \& Freire, O. B. de L. (2013) Conquistando a confiança do consumidor: minimizando o gap entre consciência ambiental e consumo ambiental. Revista de Gestão Ambiental e Sustentabilidade - GeAS, 2(2), 50-70.

Forlin, A. M., Brandalise, L. T., \& Bertolini, G. R. F. (2014) Análise do ciclo de vida do produto em uma indústria de Isopor®. Revista Gestão Sustentabilidade Ambiental, 3(1), 201-228.

Gomes, G., Gorni, P. M., \& Dreher, M. T. (2011) Consumo sustentável e o comportamento de universitários: discurso e práxis. Revista Eletrônica de Ciência Administrativa - Recadm, 10(2), 80-92.

Grohmann, M. Z., Battistella, L. F., Velter, A. N., \& Casasola, F. (2012) Comportamento ecologicamente consciente do consumidor: adaptação da escala ECCB para o contexto brasileiro. Revista de Gestão Social e Ambiental-RGSA, 6(1), 102-116.

Koenig-Lewis, N., Palmer, A., Dermody, J., \& Urbye, A. (2014) Consumers' evaluations of ecological packaging - rational and emotional approaches. Journal of Environmental Psychology, Elsevier, 37, 94-105.

Leite, P. R. (2003) Logística reversa: meio ambiente e competitividade. São Paulo: Prentice Hall.

Lemke, F., \& Luzio, J. P. P. (2014) Exploring green consumers' Mind-Set toward Green Product Design and Life Cycle Assessment: the case of skeptical brazilian and portuguese green consumers. Journal of Industrial Ecology, 18(5), 619-630.

Martins, G. de A.(2001) Estatística geral e aplicada. São Paulo: Atlas.

Monteiro, T. A., Giuliani, A. C., Zambon, M. S., Pizzinatto, N. K., \& Cunha, C. F. da. (2012) Consciência ecológica e atitudes dos consumidores: um estudo exploratório sobre seus impactos diante de produtos e marcas. Revista de Administração da Unimep, 10(3), 183-198.

Peixoto, A. F., Pereira, R. de C. de F. (2013) Discurso versus ação no comportamento ambientalmente responsável. Revista de Gestão Ambiental e Sustentabilidade - GeAS, 2(2), 71-103.

Pilger, R. R. (2013) Administração e meio ambiente. Curitiba: InterSaberes.

Raupp, F. M., Beuren, I. M. (2009) Metodologia da pesquisa aplicável às ciências sociais. In I. M. Beuren (org). Como elaborar trabalhos monográficos em contabilidade: teoria e prática, 76-97. São Paulo: Atlas.

Reyes-Ricon, M. (2010) Conhecimento e afeto ecológico: antecedentes do consumo ecológico. Dissertação de Mestrado, Fundação Getúlio Vargas, Escola Brasileira de Administração Pública e de Empresas, São Paulo, SP, Brasil. Recuperado em: 17 de fev.2015, de:

http://bibliotecadigital.fgv.br/dspace/handle/10438/7891.

Romeiro, M. do C., Prearo, L. C., \& Cordeiro, M. dos S. (2011) O comportamento de descarte seletivo do lixo domiciliar: um estudo exploratório para selecionar fatores de influência da adoção desse comportamento. Revista Gestão \& Regionalidade, 27(79), 108-123.

Stadler, A., \& Maioli, M. R. (2012) Organizações e desenvolvimento sustentável. Curitiba: InterSaberes.

Tamashiro, H. R. da S., Silveira, J. A. G. da., Mantovani, D. M. N., \& Campanário, C. R. A. de A. (2014) Aspectos determinantes do consumo de produtos cosméticos verdes. Revista de Administração e Inovação RAI, 11(1), 238-262.

Thomas, J. A., Sontag, A. G., \& Brandalise, L. T. (2014) A percepção ambiental dos industriais quanto ao ciclo de vida dos produtos (ACV). Anais do Simpósio Internacional de Gestão de Projetos, Inovação e Sustentabilidade, São Paulo, SP, Brasil, 3, novembro.

Data da submissão: 18/12/2015

Data da publicação: 30/04/2016 